\title{
RHINOLOGY
}

\section{Odontogenic sinusitis and sinonasal complications of dental treatments: a retrospective case series of 480 patients with critical assessment of the current classification}

\author{
Sinusiti odontogene e complicanze nasosinusali di trattamenti dentali: \\ una casistica retrospettiva di 480 pazienti con analisi critica della classificazione attuale

\begin{abstract}
Marco Molteni ${ }^{1}$, Antonio Mario Bulfamante ${ }^{1}$, Carlotta Pipolo ${ }^{1}$, Paolo Lozza ${ }^{1}$, Fabiana Allevi², Antonia Pisani ${ }^{1}$, Matteo Chiapasco ${ }^{3}$, Sara Maria Portaleone ${ }^{1}$, Alberto Scotti ${ }^{1}$, Alberto Maccari ${ }^{1}$, Roberto Borloni ${ }^{1}$, Giovanni Felisati ${ }^{1}$,
\end{abstract} \\ Alberto Maria Saibene ${ }^{1}$ \\ Otolaryngology Unit, Department of Health Sciences, San Paolo Hospital, University of Milan, Italy; ${ }^{2}$ Maxillofacial Unit, Department \\ of Health Sciences, San Paolo Hospital, University of Milan, Italy; ${ }^{3}$ Oral Surgery Unit, Department of Health Sciences, San Paolo \\ Hospital, University of Milan, Italy
}

\begin{abstract}
SUMMARY
The term odontogenic sinusitis (OS) has proved less and less suitable to describe a series of pathological conditions related to dental procedures. We have introduced the term and classification 'sinonasal complications of dental disease or treatment' (SCDDT). This study aimed to review our cases and evaluate whether the classification used is applicable to everyday clinical practice. The sample was composed of patients treated for SCDDT from 2002 to 2018 in our Department of Otorhinolaryngology. All presented signs and symptoms of sinusitis and had a recent history of dental disease or treatment. All patients underwent multidisciplinary evaluation, flexible endoscopy and computed tomography (CT) scan. Patients were allocated into three groups depending on the aetiology of the complication, following the classification proposed by Felisati et al. The sample comprised 480 patients (44\% men, $56 \%$ women) with a mean age of 52.36 years. Of these, 43 patients ( $9 \%$ ) belonged to group 1 (class A), $105(21 \%)$ to group $2(50,2 \mathrm{~A} ; 5,2 \mathrm{~B} ; 27,2 \mathrm{C} ; 23,2 \mathrm{D})$ and 332 $(70 \%)$ to group $3(119,3 \mathrm{~A} ; 213,3 \mathrm{~B})$. A total of 454 patients $(94.5 \%)$ had unilateral maxillary opacification, while only 26 cases $(5.4 \%)$ started as bilateral inflammation. Nine of the latter cases (34.6\%) presented a bilateral odontogenic focus, while the other $17(65.4 \%)$ had a history of unilateral dental pathology. The results of this study suggest that SCDDT is a complex entity that needs a careful diagnostic approach based on CT scans and presurgical endoscopy.
\end{abstract}

KEY WORDS: paranasal sinuses, dental diseases, transnasal endoscopic surgery

\section{RIASSUNTO}

Il termine sinusite odontogena $(\mathrm{OS})$ si è progressivamente dimostrato meno adatto a descrivere tutta una serie di condizioni patologiche legate alle procedure odontoiatriche e, per tale motivo, il nostro gruppo ha introdotto il termine "Complicanza nasosinusale di malattia o trattamento odontoiatrico" (SCDDT) e una classificazione correlata. Il presente lavoro ha lo scopo di esaminare la nostra casistica e di valutare l'applicabilità della classificazione utilizzata alla pratica clinica quotidiana. Il campione è composto da pazienti trattati per SCDDT dal 2002 al 2018 presso il nostro Dipartimento di otorinolaringoiatria. Ogni paziente presentava segni e sintomi di sinusite e aveva una recente malattia dentale o storia di trattamento. Tutti i pazienti hanno subito una valutazione multidisciplinare, un'endoscopia flessibile e una TAC. I pazienti sono stati suddivisi in tre gruppi a seconda dell'eziologia della complicanza, secondo la classificazione proposta da Felisati. Il campione era composto da 480 pazienti (44\% uomini, 56\% donne) con un'età media di 52,36 anni. 43 pazienti (9\%) appartenevano al gruppo 1 (classe A), 105 pazienti (21\%) al gruppo 2 (50, 2A; $5,2 B ; 27,2 C ; 23,2 D)$ e $332(70 \%)$ al gruppo $3(119,3 A ; 213,3 B) .454$ pazienti $(94,5 \%)$
Received: September 8, 2019

Accepted: December 24, 2019

\section{Correspondence}

Antonio Mario Bulfamante

Otolaryngology Department, San Paolo Hospital, via A. di Rudinì 8, 20142 Milan, Italy

Tel. +39028184 4249. Fax +390250323166

E-mail: antonio.bulfamante90@gmail.com

\section{Funding}

None.

Conflict of interest

The Authors declare no conflict of interest.

How to cite this article: Molteni M, Bulfamante $\mathrm{AM}$, Pipolo $\mathrm{C}$, et al. Odontogenic sinusitis and sinonasal complications of dental treatments: a retrospective case series of 480 patients with critical assessment of the current classification. Acta Otorhinolaryngol Ital 2020;40:282-289. https://doi. org/10.14639/0392-100X-N0457

(c) Società Italiana di Otorinolaringoiatria e Chirurgia Cervico-Facciale

\section{(c) (i) $(\ominus$}

This is an open access article distributed in accordance with the CC-BY-NC-ND (Creative Commons Attribution-NonCommercial-NoDerivatives 4.0 International) license. The article can be used by giving appropriate credit and mentioning the license, but only for non-commercial purposes and only in the original version. For further information: https:// creativecommons.org/licenses/by-nc-nd/4.0/deed.en 
presentavano un'opacizzazione mascellare unilaterale, con un coinvolgimento del seno mascellare sinistro in 259 casi (53,9\%) e destro in 195 casi (40,6\%), mentre solo 26 casi (5,4\%) esordivano come infiammazione bilaterale. 9 di questi ultimi (34,6\%) presentavano un interessamento odontogeno bilaterale, mentre gli altri $17(65,4 \%)$ avevano una storia di patologia dentale monolaterale. I risultati di questo studio indicano SCDDT come un'entità complessa necessitante di un approccio diagnostico basato su TAC e endoscopia prechirurgica. La nostra analisi ha evidenziato anche alcuni punti deboli dell'attuale classificazione, portando alla decisione di produrne una nuova, più pratica e applicabile.

PAROLE CHIAVE: seni paranasali, patologia dentaria, chirurgia endoscopica transnasale

\section{Introduction}

Maxillary sinusitis is inflammation of the maxillary sinus, which can be acute or chronic, based on the duration of symptoms (less or more than 12 weeks) ${ }^{1}$. While the main aetiology of sinusitis being rhinologic, dental pathology can represent the primary cause of unilateral maxillary sinusitis ${ }^{2}$. The proximity of the teeth to the floor of the sinus allows odontogenic infections to penetrate from the oral cavity to the maxillary chamber, violating the mucosal lining (Schneiderian membrane) ${ }^{3,4}$. Historically, dental diseases such as periodontitis, periodontal abscesses or periapical diseases, as well as dental trauma, have been reported to be responsible for $10-12 \%$ of maxillary sinusitis ${ }^{5,6}$, but the real incidence is now considered to be up to $30 \%^{7}$. According to recent publications, $8 \%$ of endoscopic nasal surgery aims to treat odontogenic sinusitis (OS) ${ }^{8}$. However, in recent years, the term OS has proven less and less suitable to describe a range of pathological conditions related to dental procedures, including implant displacement, oroantral communication (OAC) following dental extractions and sinus floor elevation, because these do not always lead to sinus infection or inflammation ${ }^{9}$. For this reason, in 2013 our group introduced the term "sinonasal complication of dental disease or treatment" (SCDDT) to the literature, to describe all these dental aetiologic mechanisms ${ }^{10,11}$. The clinical presentation of OS varies and is often not specific, but left untreated it may reduce quality of life and lead to serious complications. Microbiology, pathophysiology and management of odontogenic and rhinogenic sinusitis are substantially different, and OS frequently requires a multidisciplinary approach involving ear, nose and throat (ENT) specialists, maxillofacial specialists and radiologists ${ }^{12}$. When medical therapy fails, functional endoscopic sinus surgery (FESS) is required to correct sinus drainage and ventilation, while oral accesses help prevent possible relapse of infection ${ }^{13}$. Although SCDDTs have become far more common and the incidence of OS has increased ${ }^{8}$, only a few systematic studies have addressed the real rate of SCDDT and the importance of extra-maxillary extension ${ }^{8,9}$. Through analysis of a relevant case series, our study aimed to clarify this complex matter and to evaluate whether the classification used is solid and applicable to everyday clinical practice. To describe demographics of OS, aetiology, response to treatment and ease of categorisation into existing classifications, we collected a retrospective cohort of 480 consecutive patients treated for OS from 2002 to 2018 . We categorised and analysed them using the Felisati et al. classification system for sinonasal complications ${ }^{10,14}$. We also correlated clinical and radiological features with intraoperative findings to determine the real prevalence of extra-maxillary extension and reported data on surgical treatment of these patients and treatment success rates.

\section{Materials and methods}

We enrolled 480 consecutive patients treated for SCDDT from 2002 to 2018 in our Department of Otorhinolaryngology - Head and Neck Surgery (San Paolo Hospital, University of Milan, Italy). We performed a 16-year retrospective study, analysing clinical findings, demographic factors (sex and age), causes and course of disease, imaging, and surgical and medical management. This study followed the Declaration of Helsinki on medical protocol and ethics. Institutional ethics committee approval and informed consent were unnecessary, as we performed a retrospective study.

The inclusion criteria were: (1) a clinical diagnosis of sinusitis of suspected odontogenic origin, supported either by radiology or endoscopy, not responding to medical treatment; (2) ENT specialist and dentist or maxillofacial surgeon agreement on the odontogenic focus; (3) execution of an endoscopic sinus surgery procedure with or without a combined oral approach to treat the sinonasal condition; and (4) the availability of a presurgical maxillofacial computed tomography (CT) scan, with or without contrast). The exclusion criterion was a history of chronic rhinosinusitis, with or without polyps, predating the dental treatments and condition(s).

With regards to clinical findings, all patients included referred sinusitis signs and symptoms, including purulent rhinorrhoea, unilateral and bilateral nasal obstruction, maxillary pain and postnasal drip. These symptoms appeared after dental treatments or diseases and did not respond to medical therapy, which comprised topical nasal steroids and decongestants, associated with systemic antibiotic and mucolytic therapy. Nasal endoscopy with 
a flexible endoscope was performed on each patient, to explore the sinuses and identify inflammation foci, dislocated dental implants or anatomical variations (nasal polyps, septal deviation and turbinate anomalies). All these were examined and grouped as contributing causes of sinusitis. An accurate oral exam checked for dental lesions or OAC. The clinical diagnosis was confirmed by a CT scan without contrast medium (triplanar or three-dimensional) of the paranasal sinuses, which showed the location, extent and severity of the disease.

Patients were allocated into three macro-groups depending on the aetiology of the complication, following the classification protocol proposed by Felisati et al. in $2013^{10}$ (Tab. I). Group 1 included pre-implantologic treatment complications with OAC (sinus augmentation or outcomes of Le Fort osteotomies), group 2 included complications related to implant placement and group 3 included classical odontogenic complications, related to dental procedures or diseases. Each group was divided into different classes based on the clinical situation and therapeutic options. Seven classes were identified.

In our original classification, group 1 had only one class, including all complications stemming from preimplantologic treatments. Patients were not differentiated on the presence of an OAC as proposed by Fadda and colleagues ${ }^{15}$, since we regarded these patients as either having an existent $\mathrm{OAC}$ or requiring surgical creation of an OAC to approach the sinus from the combined access. Group 2 had four classes. Class 2A included all cases of peri-implant osteitis around infected endosseous or subperiosteal implants, with sinusitis and oroantral fistula. Class 2B consisted of implant dislocation into the nasal and paranasal cavities, with development of sinusitis and OAC. Class $2 \mathrm{C}$ was related to implant dislocation with sinusitis, without OAC. Class 2D included all cases in which implant dislocation had been recognised before sinusitis development.

Patients in group 3 showed OS caused by dental diseases or treatments, including pulpal necrosis in deep caries, periodontitis, odontogenic cysts, endodontic procedures and tooth extractions. These patients were further divided into two classes by the presence (3A) or absence (3B) of OAC.

The Felisati et al. classification offers also a ranking system to select the most complex patients. Class $1 \mathrm{~A}$ includes the most difficult cases to treat, and class 3B the simplest. Each patient was assigned to the highest class possible, to avoid overlaps ${ }^{10,12}$. This classification included not only bacterial but also mycotic sinonasal complications, which occurred in all three groups ${ }^{10,16}$.

All patients underwent surgery, with the choice of approach driven by the classification. A combined FESS and oral approach ${ }^{17-19}$ was required for class $1 \mathrm{~A}, 2 \mathrm{~A}, 2 \mathrm{~B}$ and $3 \mathrm{~A}$ patients. Endoscopic surgery with removal of the implant was needed for cases in class $2 \mathrm{C}$; the patients in class $3 \mathrm{~B}$ were treated only with FESS. Finally, in cases of displaced implants without sinusitis (class 2D), the treatment choice was limited to implant removal, either transnasally or transorally according to the surgeon's preference. In most cases, FESS and oral treatment of the underlying dental pathology were managed at the same surgical time.

FESS was performed under general anaesthesia, using a rigid $0^{\circ}$ endoscope. Before the surgery, intranasal vasoconstriction with nasal cottonoids soaked in mepivacaine and epinephrine $1 \%$ was essential to reduce intraoperative bleeding. The first step was the surgical correction of any significant anatomical variations (septoplasty, removal of the lateral portion of conchae bullosae, or selective bipolar cautery of hypertrophic inferior

Table I. The classification. The table shows the surgical treatment protocol according to type of complication and presents the patient numerosity in the study accordingly. In case a patient fulfils the criteria for two or more classes, he/she is assigned to the uppermost class shown in the table (designed to have on top the most difficult-to-treat scenarios and at the bottom the most easily manageable conditions, thus defining a classification priority).

\begin{tabular}{|c|c|c|c|c|c|}
\hline Groups & Classes & SCDDT patients & Treatment & $\mathrm{N}^{\circ}$ of patients & Rate $(\%)$ \\
\hline $\begin{array}{l}\text { I Preimplant treatment complications } \\
\text { Pat }\end{array}$ & $1 \mathrm{~A}$ & Sinusitis following preimplant surgery & $\begin{array}{c}\text { FESS + material removal } \\
+ \text { OAC closure }\end{array}$ & 48 & $10 \%$ \\
\hline \multirow{4}{*}{$\begin{array}{l}\text { ॥ } \\
\text { Implant treatment complications }\end{array}$} & $2 \mathrm{~A}$ & Sinusitis with perimplantitis and $\mathrm{OAC}$ & $\begin{array}{l}\text { FESS + implant removal } \\
+ \text { OAC closure }\end{array}$ & 50 & $10.4 \%$ \\
\hline & $2 B$ & $\begin{array}{c}\text { Sinusitis due to implant dislocation } \\
\text { with OAC }\end{array}$ & $\begin{array}{l}\text { FESS + implant removal } \\
+ \text { OAC closure }\end{array}$ & 7 & $1.4 \%$ \\
\hline & $2 \mathrm{C}$ & Sinusitis due to implant dislocation & FESS + implant removal & 27 & $5.7 \%$ \\
\hline & $2 \mathrm{D}$ & Implant dislocation & $\begin{array}{c}\text { Implant removal } \\
\text { (either endoscopic or transoral) }\end{array}$ & 23 & $4.8 \%$ \\
\hline \multirow{2}{*}{$\begin{array}{l}\text { III } \\
\text { Classic dental disease } \\
\text { or treatment complications }\end{array}$} & $3 A$ & OS with $O A C$ & FESS + OAC closure & 119 & $24.8 \%$ \\
\hline & 3B & OS & FESS & 213 & $44.4 \%$ \\
\hline
\end{tabular}

G: group; C: class; OS: odontogenic sinusitis; FESS: functional endoscopic sinus surgery; OAC: repair oro-antral communication repair. 
turbinates), to eliminate possible obstacles to endoscopic instrument access. Uncinectomy followed to identify the natural ostium of the maxillary sinus. After that, antrostomy was performed, enlarging the natural ostium. The maxillary sinus was then evaluated using $45^{\circ}$ or $70^{\circ}$ endoscopes to visualise the alveolar recess. Inflammation of the frontal, ethmoid and sphenoid sinuses was treated during the same endoscopic procedure to restore the normal ventilation of the paranasal cavities. When the FESS was completed, the intraoral approach promoted the closure of the OAC and the removal of grafting materials, infected implants or necrotic teeth, not easily reachable using endoscopic access.

Patients were usually discharged the day after surgery. After surgical treatment, antibiotic therapy was recommended. Oral administration of a quinolone, such as levofloxacin $500 \mathrm{mg}$, once a day for 10 days, is effective to prevent any recurrence of symptoms. Patients were invited to continue nasal washes with saline three times a day for around 30 days after surgery. Topical antibiotic creams and local steroids were indicated in all patients. Mouth rinses, such as chlorhexidine $0.2 \%$, were recommended after dental surgery to maintain oral hygiene. To rule out recurrence of infection, patients were followed up with endoscopic controls at 7, 30 and 90 days after surgery. Treatment success was defined as endoscopic absence of signs of sinusitis and subjective symptom resolution reported by patients.

\section{Results}

A total of 480 patients, diagnosed with sinusitis and treated with surgery from 2002 to 2018, were included in our retrospective study. Of these, 212 were men $(44 \%)$ and 268 were women $(56 \%)$, a male to female ratio of $8: 10$. The mean age was 52.36 years, with the youngest patient 16 years and the oldest 86 years. A history of previous oral surgery or dental disease was reported by all patients. The dental origin was confirmed by analysing the patients' medical history, oral examination and imaging. The most commonly reported symptoms were unilateral purulent rhinorrhoea $(64 \%)$ and unilateral $(71 \%)$ or bilateral $(29 \%)$ nasal obstruction, followed by maxillary pain and postnasal drip. A CT scan was performed in all cases before surgical treatment ${ }^{20}$. The maxillary sinus was predominantly involved: 454 patients $(94.5 \%)$ had unilateral maxillary opacification, while only 26 cases (5.4\%) began as bilateral inflammation. Nine of these latter cases (34.6\%) presented a bilateral odontogenic focus, while the remaining 17 (65.4\%) had a history of unilateral dental pathology. Overall, extramaxillary extension was observed in 305 patients (63.5\%). In group 1, 33 patients showed extra-maxillary involvement (69\%), along with 57 (53\%) in group 2, and $215(65 \%)$ in group 3. Unilateral interest of ethmoidal cells was found in 294 cases $(61.25 \%$ ), and bilateral in 34 cases (7\%); spread of infection to the frontal and sphenoid sinuses was reported in $75(15.6 \%)$ and $19(4 \%)$ patients respectively. In 11 cases, infection was detected in all paranasal sinuses, resulting in pansinusitis (Tab. II).

All patients underwent careful presurgical evaluation with a flexible endoscope to detect concomitant anatomical anomalies, such as nasal septal deviation (37 cases), inferior turbinate hypertrophy and/or concha bullosa (50 cases), or nasal polyps (46 cases). The patients were grouped according to the Felisati et al. classification of SCDDT $^{8}$, with 43 patients (9\%) in group 1 (class A), 105 $(21 \%)$ in group $2(50,2 \mathrm{~A} ; 5,2 \mathrm{~B} ; 27,2 \mathrm{C} ; 23,2 \mathrm{D})$ and 332 $(70 \%)$ in group $3(119,3 \mathrm{~A} ; 213,3 \mathrm{~B})$. Concerning aetiology of dental diseases and routine dental procedures, exclusive sinus infection without OAC (3B) was the most common cause of SCDDT (213 out of 480, 44\%). Pre-implant treatment complications (group 1) were the basis of these problems, including 45 cases $(9.4 \%)$ of complicated sinus floor elevation procedures and three cases $(0.6 \%)$ of Le Fort I osteotomies. Analysis of the oral cavity by a dentist identified that $\mathrm{OAC}$ alone was present and the cause of OS in 224 patients (45.8\%), distributed among classes $1 \mathrm{~A}, 2 \mathrm{~A}, 2 \mathrm{~B}$ and $3 \mathrm{~A}$. A further 50 cases $(10.4 \%)$ of peri-implant osteitis with OAC (class 2A) were detected. Finally, we diagnosed 57 cases $(11.9 \%)$ of OS for implant displacement: seven (1.5\%) with sinusitis and OAC (2B), 27 (5.6\%) with sinusitis without OAC (2C) and 23 (4.8\%) without sinusitis (2D).

The main therapeutic approach consisted of FESS, with or without the need for dental treatments. Our endoscopic protocol followed different steps: an uncinectomy, a middle antrostomy and, when the infection was extended to the ethmoidal cells or frontal sinuses, an ethmoidectomy or frontal ostium opening. Anterior and/or posterior ethmoidectomy was performed in 294 patients (61.2\%), while the patency of frontal sinuses was restored in 75 patients (15.6\%). A combination of endoscopic endonasal access with an intraoral approach was performed in 311 patients $(64.8 \%)$, while FESS alone was preferred in 169 cases (35.2\%). No patient underwent an exclusive intraoral approach. A total of $171(35.6 \%)$ had to be treated for persistent OAC, surgically closed with local flaps (Rehrmann or Bichat's fat pad flap). Classic Caldwell-Luc surgery (removal of part of the anterior lateral wall of the maxillary sinus) was performed in only one case, belonging to class $2 \mathrm{~B}$. For this patient, the sinusitis was related to a foreign body (implant dislocated) and treatment required an external approach with the collaboration of a maxillofacial surgeon. Concerning dental approaches, 478 patients 
Table II. The sinus involvement. The table shows the involvement of the maxillary, the ethmoid, the frontal and the sphenoid sinuses, both unilaterally and bilaterally.

\begin{tabular}{|c|c|c|c|c|c|}
\hline Sinus involved & Unilateral & $\%$ & Bilateral & $\%$ & Total \\
\hline Maxillary & 454 & $94.5 \%$ & 26 & $5.5 \%$ & 480 \\
\hline Ethmoid & 260 & $54 \%$ & 34 & $7 \%$ & 294 \\
\hline Frontal & 68 & $14 \%$ & 7 & $1.5 \%$ & 75 \\
\hline Sphenoid & 16 & $3 \%$ & 3 & $0,6 \%$ & 19 \\
\hline
\end{tabular}

underwent preoperative dental care, not resolving the sinusitis, and only two underwent postoperative dental treatment.

The rate of general complications was low, and no major intraoperative complications were observed. The failure of treatment was described in only eight cases (1.7\%): three belonging to class $3 \mathrm{~A}$, two to class $3 \mathrm{~B}$, two to class $1 \mathrm{~A}$ and one to class $2 \mathrm{~A}$. Five of them $(1.1 \%)$ reported a recurrence of inflammation, some months after the surgery. In three cases $(0.6 \%)$, antibiotic management was therapeutic, while the two others $(0.4 \%)$ underwent new endoscopic surgery. Two patients $(0.4 \%)$ required a revision under general anaesthesia to repair an oroantral fistula, within two months after the initial surgery. One case $(0.2 \%)$ of bleeding occurred one hour after the surgical procedure, requiring a revision of haemostasis under general anaesthesia.

The follow-up period was between one and two years, with an average of almost 18 months. Endoscopic examination during follow-up was performed seven and 30 days after surgery and then every three months, with excellent longterm results in terms of endoscopic findings and subjective symptom resolution.

\section{Discussion}

The importance of odontogenic foci as a cause of chronic sinusitis has frequently been reported in the literature. Although rhinogenic aetiology remains the main cause of sinusitis, OS has recently increased, likely due to the increase in dental treatments and the consequent increase in sinonasal complications.

In this wide panorama of studies and data, our group has always stood out for its positive contributions to detecting and treating pathological and functional nasal conditions ${ }^{14}$. With this study, we present our experience and propose a protocol of treatment centred on FESS. Although other studies have been published concerning the endoscopic approach to sinusitis ${ }^{13}$, the case series have often been limited and the data restricted ${ }^{21}$. Instead, this review includes the largest number of surgical cases ever reported (480 patients), obtained over more than 16 years of research, and examines a variegated population of patients affected by SCDDT. As we have noted, the term OS should be considered superseded, since in 2013 we coined the name
SCDDT, which best describes its vastness. Other studies have referred to the Felisati et al. classification, so it is of interest to compare the different results ${ }^{6,15}$. Furthermore, we would like to critically evaluate its applicability in everyday practice.

Fadda et al. ${ }^{15}$ showed that, in most patients, conventional dental disease or treatment complications (group 3) were the main factors driving sinonasal complications $(45 \%$ of their patients). In our cohort, these data are even more clear, with 332 patients $(70 \%)$ belonging to group 3 (A, B; Fig. 1). Examining numerous cases, we can see how the percentage of patients in group 3 is drastically increasing over time.

Some studies have reported a gradual increase in the incidence of sinusitis as a complication of dental implants and, for some authors ${ }^{6}$, dental implant-related complications must even be considered as the main cause of SCDDT. In our experience, complications related to implant dentistry affected 107 of 480 cases (22.3\%; group 2). The subclassification included 50 patients $(10.5 \%)$ in class $2 \mathrm{~A}$ with peri-implant infections, while the other three classes comprised all the cases of dislocated implants $(2 \mathrm{~B}, 1.5 \%$; $2 \mathrm{C}, 5.7 \% ; 2 \mathrm{D}, 4.8 \%$ ). As group 3 was the largest, with 332 patients $(70 \%)$, we still consider classical dental diseases and complications of dental treatments the main cause of SCDDT.

Whether the main cause of SCDDT or not, dental implants pose important issues in OS, particularly concerning its management. Due to the important healthcare and economic burden imposed on patients by implantology, carefully evaluating the possibility to maintain the implants is clearly important. Nevertheless, we are firmly convinced that in cases of suspected peri-implant osteitis

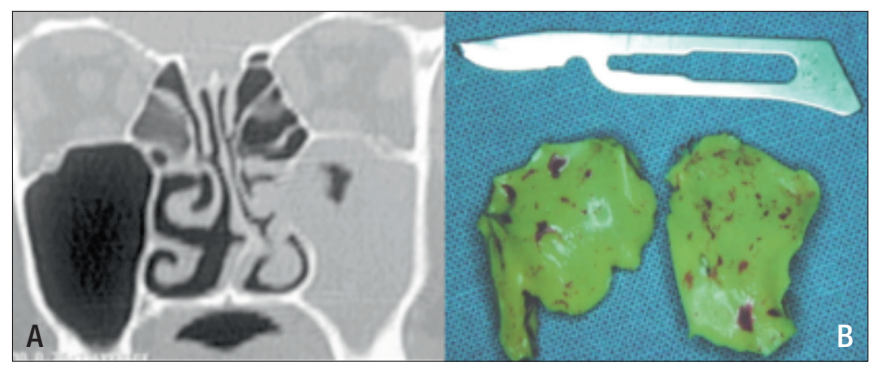

Figure 1. (A) CT and aspect of a foreign body unilateral maxillary sinusitis, due to the penetration of moulding material used for the prosthetic rehabilitation right after dental extraction - class 3A; (B) the extracted moulding material. 
or dubious complete osseointegration, the implant should be removed, in order to minimise the risk of relapse of sinusitis ${ }^{14}$. Implant removal often reveals underlying OAC, usually derived from a pre-existing communication, caused by iatrogenic manoeuvres. OAC is a cause of sinonasal infection because it favours the migration of bacteria from the oral cavity ${ }^{3}$. In our cohort, 224 patients, belonging to classes 1A, 2A, 2B and 3A, had developed an OAC after dental surgical procedures. The closure of OAC was performed with local flaps as Rehrmann flap, formed from the mucoperiosteum of the maxillary bone, or with a buccal fat pad flap ${ }^{1,3}$. In particular, the latter was often our first choice, due to its low morbidity and high resistance. No episodes of wound dehiscence or other significant complications were reported. While some authors propose that small OACs might heal spontaneously after correct endoscopic treatment of the sinusitis, we chose to perform OAC closure no matter the size of the defect, to maximise chances of healing after a single procedure, and because dislocated implants in the absence of sinusitis can be successfully retrieved transnasally or transorally. The latter approach has been accomplished with a number of different techniques worth mentioning: canine fossa puncture ${ }^{22,23}$, which evolved into the use of antral retrievers ${ }^{18}$ and the elevation of osteoplastic flaps ${ }^{24}$.

To perform implant dentistry, a sufficient bone amount is necessary ${ }^{25,26}$. If this condition is unsatisfied, it is possible to perform a sinus floor elevation or sinus lift, a bone augmentation procedure that inserts bone graft material into a newly created space between the maxillary bone and Schneiderian membrane through a lateral or crestal access $12,27,28$. Sinus floor elevation is now considered a routine treatment and widespread, so more complications are arising from its use ${ }^{27}$. When the integrity of the sinus membrane is damaged and grafting material migrates into the cavity, bacterial contamination is favoured, resulting in infection of the sinus. Our group treated 48 cases of SCDDT that occurred after sinus lift surgery (class 1). All patients underwent endoscopic widening of the maxillary natural ostium with closure of the OAC ${ }^{29}$.

Due to the complexity of SCDDT, diagnostic workup is fundamental to select the best multidisciplinary team for each case ${ }^{30}$. The first step is examination of the patient and their medical history and symptoms, usually performed by an ENT surgeon. After that, almost all our patients underwent presurgical nasal and upper airway endoscopy, to examine possible anatomical variations or evaluate the extent of the pathology, as well as radiological evaluation. A maxillofacial CT scan constituted a confirmatory diagnostic tool in all our patients, and this should be considered essential, even when the diagnosis is almost self-evident. It can also help quickly locate a foreign body or an implant within the maxillary sinus ${ }^{31}$. Further, CT is fundamental to evaluate the involvement of other paranasal sinuses. Previous studies have described ethmoidal cell involvement, reporting a limited number of cases ${ }^{21,32}$. Our study evaluated not only the prevalence of ethmoid engagement but also that of the frontal and sphenoid sinuses (Tab. II): a total of 305 patients $(63.5 \%)$ presented extra-maxillary spread of infection. The sinus most affected by pathogenic dissemination was the ethmoid, in 294 cases out of 305 , followed by the frontal $(n=75)$ and sphenoid sinuses $(\mathrm{n}=19)$. In cases of bilateral spread of OS, 26 of 480 patients $(5.5 \%)$ showed isolated maxillary contralateral diffusion, which in 34 patients $(7 \%)$ expanded further to ethmoidal cells, in three $(0.6 \%)$ to the sphenoid sinus and in another seven (1.5\%) to the frontal sinus (Tab. II). From this data, it appears that once the infection exits the maxillary sinus it fills firstly the closest and most vulnerable ethmoidal cells, then the frontal and only finally the sphenoid sinuses.

Concerning diagnosis of OS, usually physical exam, endoscopy and triplanar or 3D CT slices provide all the information needed for adequate surgical planning, but complementary cone beam CT (CBCT) could be also prescribed by dentists in selected cases due to the greater bone resolution of CBCT than normal CT (Fig. 2) ${ }^{15,33}$. Another test that can help dentists in the diagnostic pathway is orthopantomogram (OPG), which may help assess the correct surgical approach for treating dental conditions behind sinus inflammation (Fig. 3). A combined approach is useful to recover the natural sinus homeostasis, eliminate dental pathologies and prevent possible complications or recurrence.

In our experience, FESS, combined if necessary with an external approach, seems to be the most appropriate treatment to resolve sinus inflammation. Furthermore, FESS allows

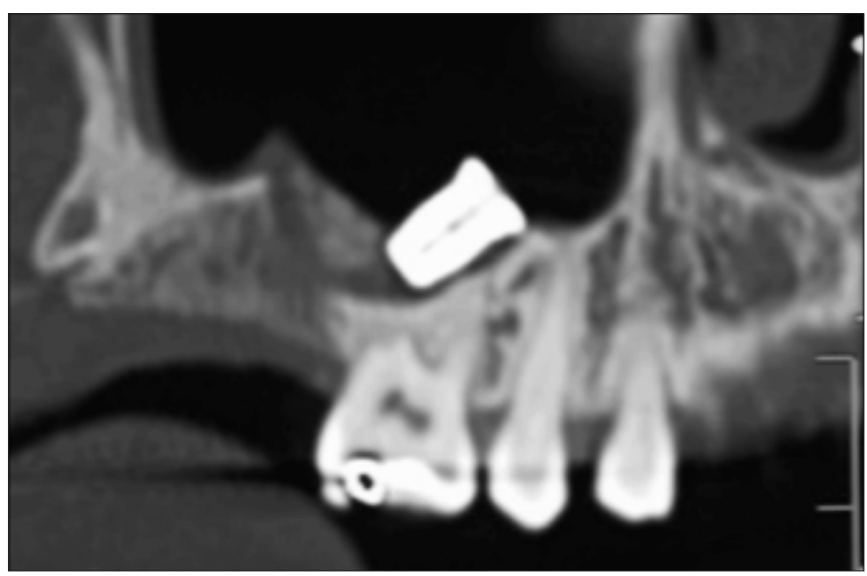

Figure 2. A Cone Beam Computed Tomography of a dental implant displaced into the maxillary sinus, without any signs of sinusitis - class 2D. 


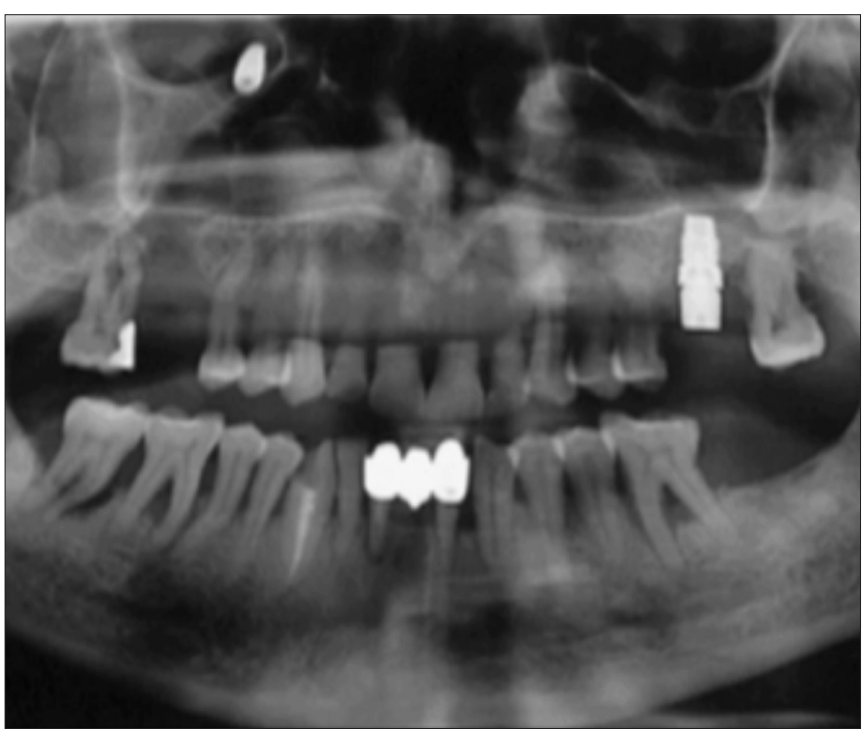

Figure 3. An orthopantomogram of a maxillary sinusitis following implant displacement into maxillary sinus - class 2C.

the management of all the other sinuses and treatment of anatomic alterations that can worsen normal sinus clearance and drainage. Therefore, in one surgical stage, it is possible to resolve the acute inflammation, prevent exacerbations and promote functional recovery of the sinus.

The intraoral access makes it possible to reach the sinus parts that are not easy to manage with nasal endoscopic view only, such as the alveolar recess ${ }^{21,31}$. Additionally, it allows the treatment of external sources of infection, and it is evident that treating the infected teeth plays a fundamental role in the prevention of recidivism.

The percentage of postoperative complications we reported was less than $1 \%$, made up of $62.5 \%$ sinusitis recurrence, $25 \%$ OAC recurrence and $12.5 \%$ postsurgical bleeding. Moreover, FESS results are more effective in respecting the physiological sinus functions and correcting the cofactors of infection, including anatomical anomalies that can worsen the sinus drainage, such as concha bullosa, inferior turbinate hypertrophy or septal deviation. These findings suggest that, when pharmacological and conservative treatments fail, an endoscopic approach is not only valid but also safe.

One limitation of the present study lies in the lack of microbiological examination, except for patients with radiological findings of fungus ball (iron-like signal), in which mucosal biopsy is performed routinely in our centre. Other studies have been published concerning the microbiological and biochemical characterisation of OS, and its antibiotic susceptibility, but this was not the aim of our study $3,10,34,35$.

After completing the review of our past cases, we decided to focus attention on the classification itself and its applicability, and the results were conflicting. Certainly, it is complete and, being based on SCDDT aetiology, makes it easy to allocate every patient to the corresponding group and class. However, the number of groups and classes (respectively three and eight) can easily lead to confusion and misleading analysis of data. As a consequence, the choice of correct therapeutic approach can be difficult. Considering these issues, the present classification seems to many colleagues impractical and not suitable for everyday application. Moreover, we realised that, although it was developed to describe a multidisciplinary medical condition (SCDDT), it was mainly directed to otorhinolaryngologists, not considering, for example, SCDDT only requiring an isolated oral approach. Certainly, we could have simply added another group or class to the existing ones, but this would only lead to further complication. Apart from these considerations, the classification has not encountered widespread use for these pathologies, and therefore a newly devised classification, possibly approach-based and not aetiology-based, could be implemented to streamline case categorisation and comparison of surgical results between different rhinologic groups.

\section{Conclusions}

According to our experience and to the data reported herein, SCDDT is not always limited to a unilateral maxillary cavity but often reaches other paranasal sinuses. As a consequence, a careful diagnostic approach based on CT scans and presurgical endoscopy must be considered fundamental. It is our opinion that a combined surgical approach, developed through multidisciplinary collaboration between ENT and oral surgeons, represents the best treatment option to achieve solid success rates. On the other hand, our analysis has also shown some weak points of the current classification, highlighting the need to produce a new one that is more practical and suitable.

\section{References}

Mehra P, Murad H. Maxillary sinus disease of odontogenic origin. Otolaryngol Clin North Am 2004;37:347-64. https://doi.org/10.1016/ s0030-6665(03)00171-3

2 Kuan EC, Suh JD. Systemic and odontogenic etiologies in chronic rhinosinusitis. Otolaryngol Clin North Am 2017;50:95-111. https:// doi.org/10.1016/j.otc.2016.08.008

3 Saibene AM, Vassena C, Pipolo C, et al. Odontogenic and rhinogenic chronic sinusitis: a modern microbiological comparison. Int Forum Allergy Rhinol 2016;6:41-5. https://doi.org/10.1002/alr.21629

4 Cordero GB, Ferrer SM, Fernández L. Odontogenic sinusitis, oroantral fistula and surgical repair by Bichat's fat pad: literature review. Acta Otorrinolaringologica (English Edition) 2016;67:107-13. https://doi.org/10.1016/j.otoeng.2016.03.009 
5 Pearlman AN, Conley DB. Review of current guidelines related to the diagnosis and treatment of rhinosinusitis. Curr Opin Otolaryngol Head Neck Surg 2008;16:226-30. https://doi.org/10.1097/ MOO.0b013e3282fdcc9a

6 Kim SJ, Park JS, Kim HT, et al. Clinical features and treatment outcomes of dental implant-related paranasal sinusitis: a 2-year prospective observational study. Clin Oral Implants Res 2016;27:e100-4. https://doi.org/10.1111/clr.12570

7 Patel NA, Ferguson BJ. Odontogenic sinusitis: an ancient but under-appreciated cause of maxillary sinusitis. Curr Opin Otolaryngol Head Neck Surg 2012;20:24-8. https://doi.org/10.1097/ MOO.0b013e32834e62ed

8 Hoskison E, Daniel M, Rowson JE, et al. Evidence of an increase in the incidence of odontogenic sinusitis over the last decade in the UK. J Laryngol Otol 2012;126:43-6. https://doi.org/10.1017/ S0022215111002568

9 Costa F, Emanuelli E, Robiony M, et al. Endoscopic surgical treatment of chronic maxillary sinusitis of dental origin. J Oral Maxillofac Surg 2007;65:223-8. https://doi.org/10.1016/j.joms.2005.11.109

10 Felisati G, Chiapasco M, Lozza P, et al. Sinonasal complications resulting from dental treatment: outcome-oriented proposal of classification and surgical protocol. Am J Rhinol Allergy 2013;27:e101-6. https://doi.org/10.2500/ajra.2013.27.3936

11 Pipolo C, Felisati G, Saibene AM. Sinonasal complications of dental disease or treatment coming out of the c.l.o.s.e.t. Clin Otolaryngol 2016;41:100. https://doi.org/10.1111/coa.12521

12 Felisati G, Saibene AM, Lenzi R, et al. Late recovery from foreign body sinusitis after maxillary sinus floor augmentation. BMJ Case Rep 2012;2012. https://doi.org/10.1136/bcr-2012-007434

13 Di Pasquale D, Saibene AM, Bebi V, et al. Calcifications afloat: bad omens in maxillary sinus augmentation. BMJ Case Rep 2013;2013. https://doi.org/10.1136/bcr-2013-201581

14 Saibene AM, Collurà $\mathrm{F}$, Pipolo $\mathrm{C}$, et al. Odontogenic rhinosinusitis and sinonasal complications of dental disease or treatment: prospective validation of a classification and treatment protocol. Eur Arch Otorhinolaryngol 2019;276:401-6. https://doi.org/10.1007/s00405-018-5220-0

15 Fadda GL, Berrone M, Crosetti E, et al. Monolateral sinonasal complications of dental disease or treatment: when does endoscopic endonasal surgery require an intraoral approach? Acta Otorhinolaryngol Ital 2016;36:300-9. https://doi.org/10.14639/0392-100X-904

16 Tomomatsu N, Uzawa N, Aragaki T, et al. Aperture width of the osteomeatal complex as a predictor of successful treatment of odontogenic maxillary sinusitis. Int J Oral Maxillofac Surg 2014;43:138690. https://doi.org/10.1016/j.ijom.2014.06.007

17 Saibene AM, Lozza P. Endoscopic sinus surgery and intraoral approaches in sinus oral pathology. J Craniofac Surg 2015;26:322-3. https://doi.org/10.1097/SCS.0000000000001223

18 Mantovani M, Pipolo C, Messina F, et al. Antral retriever and displaced dental implants in the maxillary sinus. J Craniofac Surg 2011;22:2275-7. https://doi.org/10.1097/SCS.0b013e3182327125

19 Procacci P, Lanaro L, Molteni G, et al. Trans-nasal endoscopic and intraoral combined approach for odontogenic cysts. Acta Otorhinolaryngol Ital. 2018;38:439-44. https://doi.org/10.14639/0392-100X-1915

20 Saibene AM, Pipolo GC, Lozza P, et al. Redefining boundaries in odontogenic sinusitis: a retrospective evaluation of extramaxillary involvement in 315 patients. Int Forum Allergy Rhinol 2014;4:1020-3. https://doi.org/10.1002/alr.21400
21 Shahbazian M, Jacobs R. Diagnostic value of 2D and 3D imaging in odontogenic maxillary sinusitis: a review of literature. J Oral Rehabil 2012;39:294-300. https://doi.org/10.1111/j.1365-2842.2011.02262.x

22 Sireci F, Dehgani Mobaraki P, et al. Indications to canine fossa puncture in management of maxillary sinusitis: review of literature. CEPAL Review 2017:2759-62.

23 Albu S, Baciut M, Opincariu I, et al. The canine fossa puncture technique in chronic odontogenic maxillary sinusitis. Am J Rhinol Allergy 2011;25:358-62.

24 Biglioli F, Goisis M. Access to the maxillary sinus using a bone flap on a mucosal pedicle: preliminary report. J Craniomaxillofac Surg 2002;30:255-9.

25 Testori T, Weinstein T, Taschieri S, et al. Risk factors in lateral window sinus elevation surgery. Periodontol 2000 2019;81:91-123. https://doi.org/10.1111/prd.12286

26 Mahesh L, Agarwal A, Guirado JC, et al. Survival of implants after indirect maxillary sinus elevation procedure: a two years longitudinal study. J Contemp Dent Pract 2019;20:504-7. https://www.ncbi.nlm. nih.gov/pubmed/31308285

27 Chiapasco M, Felisati G, Zaniboni M, et al. The treatment of sinusitis following maxillary sinus grafting with the association of functional endoscopic sinus surgery (FESS) and an intra-oral approach. Clin Oral Implants Res 2013;24:623-9. https://doi.org/10.1111/j.16000501.2012.02440.x

28 Saibene AM, Pipolo C, Maccari A, et al. One-step maxillary sinus augmentation in association with endoscopic sinus surgery: case series and review of the literature. Implant Dent 2016;25:698-702. https://doi.org/10.1097/ID.0000000000000477

29 Lopatin AS, Sysolyatin SP, Sysolyatin PG, et al. Chronic maxillary sinusitis of dental origin: is external surgical approach mandatory? Laryngoscope 2002;112:1056-9. https://doi.org/10.1097/00005537200206000-00022

30 Felisati G, Saibene AM, Pipolo C, et al. Implantology and otorhinolaryngology team-up to solve a complicated case. Implant Dent 2014;23:617-21. https://doi.org/10.1097/ID.0000000000000146

31 Chiapasco M, Felisati G, Maccari A, et al. The management of complications following displacement of oral implants in the paranasal sinuses: a multicenter clinical report and proposed treatment protocols. Int J Oral Maxillofac Surg 2009;38:1273-8. https://doi.org/10.1016/j. ijom.2009.09.001

32 Nair UP, Nair MK. Maxillary sinusitis of odontogenic origin: conebeam volumetric computerized tomography-aided diagnosis. Oral Surg Oral Med Oral Pathol Oral Radiol Endod 2010;110:e53-7. https://doi.org/10.1016/j.tripleo.2010.06.020

33 Felisati G, Borloni R, Chiapasco M, et al. Reply to: "the ENT's role in sinus lift management doesn't need misleading messages.” Acta Otorhinolaryngol Ital 2013;33:47-8. https://www.ncbi.nlm.nih.gov/ pubmed/23620640

34 Workman AD, Granquist EJ, Adappa ND. Odontogenic sinusitis: developments in diagnosis, microbiology, and treatment. Curr Opin Otolaryngol Head Neck Surg 2018;26:27-33. https://doi.org/10.1097/ MOO.0000000000000430

35 Drago L, Vassena C, Saibene AM, et al. A case of coinfection in a chronic maxillary sinusitis of odontogenic origin: identification of dialister pneumosintes. J Endod 2013;39:1084-7. https://doi. org/10.1016/j.joen.2013.04.025 